\title{
Estimates of heritability and genotype-environment interactions for body weight in sea bass (Dicentrarchus labrax L.) raised under communal rearing conditions
}

\author{
Eric Saillant $^{\mathrm{a}, \mathrm{b}_{*}}$, Mathilde Dupont-Nivet ${ }^{\mathrm{c}}$, Pierrick Haffray ${ }^{\mathrm{d}}$, Béatrice Chatain \\ ${ }^{\mathrm{a} 9}$ Laboratoire de Recherche en Pisciculture Marine, IFREMER, Chemin de Maguelonne 34250, 10 Palavas-les- \\ Flots, France \\ ${ }^{b} 11$ Ecloserie Marine de Gravelines, Voie des Enrochements, 59820, Gravelines, France \\ '12 INRA, Laboratoire de génétique des poissons, 78352 Jouy en Josas, Cedex, France \\ d 13 SYSAAF, Section aquacole, Station SCRIBE, Campus de Beaulieu, 35042, Rennes, France \\ * Corresponding author : Present address: Department of Wildlife and Fisheries Sciences, TAMU \\ 2258, Texas A\&M University, College Station, Texas 77843-2258. U.S.A.. email: esaillant@tamu.edu
}

\begin{abstract}
Genetic parameters for somatic growth rate in sea bass were estimated in two experiments where 27 (year-class 1997)-30 (year-class 1998) families of sea bass (3 dams mated with 9-10 sires according to a full factorial design) were raised mixed in the same tanks starting shortly before hatching (48h post fertilization). Trials were performed under two temperature (experiment 1, 1997: group High Temperature HT and group Low Temperature, LT) and two density regimes (experiment 2, 1998: group High Density, HD and group Low Density, LD) with a subset of the mating design (18 families) being reproduced in the two experiments. All the fish were genotyped at 3-6 microsatellite loci which allowed them to be assigned to the individual breeders used in the mating design. Heritability of (log transformed) body weight was estimated from the sire component of variance at a mean size of 20.0-21.6 cm (Standard length) using a simple additive model and a Restricted Maximum Likelihood algorithm. Estimates were $0.31 \pm 0.12$ (group HT and group HD), $0.50 \pm 0.19$ (group low temperature, $\mathrm{LT}$ ) and $0.60 \pm 0.22$ (grouplow density, LD) while a noverall estimate using data from both yearclasses was $0.29 \pm 0.22$ indicating an important additive genetic component in growth rate of the sea bass in all conditions. Correlations of the Estimated Breeding Values (EBV) of the sires between treatments/years were moderate (range 0.01-0.51) suggesting the occurrence of genotype $x$ environment effects. Growth was followed from the age of 341 days post fertilization (dpf) (mean standard length, $\mathrm{SL} \pm$ S.D. $16.0 \pm 1.9 \mathrm{~cm}$ ) to the age of $818 \mathrm{dpf}($ mean SL $32.6 \pm 3.1 \mathrm{~cm}$ ) in the HT group. h2 estimates tended to increase with the age of the fish $(0.21 \pm 0.10$ at $341 \mathrm{dpf}$ to $0.56 \pm 0.20$ at $818 \mathrm{dpf}, \mathrm{rs}=0.90, \mathrm{P}=0.04$ ). Genetic correlations among log weights recorded at various ages were high (range 0.61-0.85, average 0.70 ) indicating stability of the genetic values throughout the growth phase sampled and that growth as estimated at the earliest stage examined ( $341 \mathrm{dpf}, 90 \mathrm{~g}$ ) can be used as a predictor of later progeny growth (until $818 \mathrm{dpf}, 737 \mathrm{~g}$ ).
\end{abstract}

Keywords: heritability, growth, Dicentrarchus labrax, microsatellites markers, communal rearing, genotype $\mathrm{x}$ environment interaction. 


\section{Estimates of heritability and genotype-}

2 environment interactions for body weight in sea

${ }^{a}$ Laboratoire de Recherche en Pisciculture Marine, IFREMER, Chemin de Maguelonne 34250,

${ }^{\mathrm{b}}$ Ecloserie Marine de Gravelines, Voie des Enrochements, 59820, Gravelines, France

c INRA, Laboratoire de génétique des poissons, 78352 Jouy en Josas, Cedex, France

\section{Abstract}

*Corresponding author, Present address: Department of Wildlife and Fisheries Sciences, TAMU 2258, Texas A\&M University, College Station, Texas 77843-2258. U.S.A.. email: esaillant@tamu.edu 
Genetic parameters for somatic growth rate in sea bass were estimated in two experiments where 27 (year-class 1997)-30 (year-class 1998) families of sea bass (3 dams mated with 9-10 sires according to a full factorial design) were raised mixed in the same tanks starting shortly before hatching (48h post fertilization). Trials were performed under two temperature (experiment 1, 1997: group High Temperature HT and group Low Temperature, LT) and two density regimes (experiment 2, 1998: group High Density, HD and group Low Density, LD) with a subset of the mating design (18 families) being reproduced in the two experiments. All the fish were genotyped at 3-6 microsatellite loci which allowed them to be assigned to the individual breeders used in the mating design. Heritability of (log transformed) body weight was estimated from the sire component of variance at a mean size of 20.0-21.6 cm (Standard length) using a simple additive model and a Restricted Maximum Likelihood algorithm. Estimates were $0.31 \pm$ 0.12 (group HT and group HD), $0.50 \pm 0.19$ (group low temperature, LT) and $0.60 \pm 0.22$ (group low density, LD) while an overall estimate using data from both year-classes was $0.29 \pm 0.22$ indicating an important additive genetic component in growth rate of the sea bass in all conditions. Correlations of the Estimated Breeding Values (EBV) of the sires between treatments/years were moderate (range 0.01-0.51) suggesting the occurrence of genotype $\mathrm{x}$ environment effects.

Growth was followed from the age of 341 days post fertilization (dpf) (mean standard length, $\mathrm{SL} \pm$ S.D. $16.0 \pm 1.9 \mathrm{~cm})$ to the age of $818 \mathrm{dpf}($ mean SL $32.6 \pm 3.1 \mathrm{~cm})$ in the HT group. $h^{2}$ estimates tended to increase with the age of the fish $(0.21 \pm 0.10$ at $341 \mathrm{dpf}$ to $0.56 \pm 0.20$ at 818 dpf, $r s=0.90, P=0.04)$. Genetic correlations among log weights recorded at various ages were high (range 0.61-0.85, average 0.70) indicating stability of the genetic values throughout the growth phase sampled and that growth as estimated at the earliest stage examined (341 dpf, 90g) can be used as a predictor of later progeny growth (until $818 \mathrm{dpf}, 737 \mathrm{~g}$ ). 
Keywords: heritability, growth, Dicentrarchus labrax, microsatellites markers, communal rearing, genotype x environment interaction.

2

3

4

5

6

7

8

9

10

11

12

\section{Introduction}

The European sea bass (Dicentrachus labrax) is an economically important fish cultivated mostly along the Mediterranean coast. Domestication was initiated at the beginning of the 80's and farms are currently developing selective breeding programs designed to improve characters of commercial interest. Growth rate is one of the primary characters of interest in such programs as production costs can be significantly lowered by reducing the duration of the rearing cycle. The optimization of selection program requires knowledge of genetic parameters of characters as optimal selection strategies depend primarily on heritability of individual characters and genetic correlations between characters (Falconer and McKay, 1989). A good knowledge of the extent of genotype environment interactions also is useful as such interactions can be a limit to the diffusion of genetic progress if selected strains do perform differently according to the site where they are grown. They can also limit genetic progress if environmental conditions vary with time within a single site where selection would be implemented.

Potential for selection for increased growth rate has been examined in several fish species of interest for aquaculture (e.g. Knibb, 1998; Wohlfarth and Hulata, 1989; Gjedrem, 2000) and appears to be limited by early common environmental effects that can be confounded with genetic values thus preventing accurate evaluation of these values unless large numbers of replicate tanks are used (Vandeputte et al., 2001). The advent of molecular markers such as microsatellites allows to identify the pedigrees of multiple progenies raised mixed in the same 
tank; thereby, multiple families can be tested under identical conditions (in the same tank) from very early life stages such as fertilization when physical tagging is not possible (Herbinger et al., 1995; Garcia de Leon et al., 1998; Estoup et al., 1998). Based on this principle, genetic parameters can be estimated using a limited number of tanks in the absence of early common environment effects (Vandeputte et al., 2001; Chevassus et al., 2002).

Few publications assessed genetic variability of sea bass growth rate. Garcia de Leon et al. (1998) found a significant sire effect on body size reached at the age of 116 days and a precocious and transient dam effect on body size that was significant at the ages of 11 and 40 days respectively. However, fish were grown for 116 days only during the experiment and analysis of sire and dam effect was based on a limited mating design (three dams $\mathrm{x}$ three sires factorial design). Gorshkov et al. (2004) report differences between growth rates of strains of sea bass grown from 40-50g to 270 and $520 \mathrm{~g}$ indicating the occurrence of genetic variability for growth rate during the corresponding growth phases. However, to our knowledge, there is no report to date of heritability and $\mathrm{G} \times \mathrm{E}$ interactions for growth rate in sea bass captive populations. Here we estimate heritability of growth rate in 27-30 families of sea bass raised mixed in the same tanks from fertilization and using a posteriori parentage assignment with microsatellites in order to obtain parameters unbiased by early common environment effects. $h^{2}$ was estimated at various ages starting at the end of pre-growing and ending at a commercial size of $750 \mathrm{~g}$. We also examined genetic correlation across different environment and across years in order to give a first assessment of $\mathrm{G}$ x $\mathrm{E}$ interactions in sea bass.

\section{Materials and methods}




\subsection{Experimental groups (Figure 1)}

The studied groups were constituted of 27 and 30 families of sea bass raised mixed in the same tank from $48 \mathrm{~h}$ post fertilization (i.e. shortly before hatching) until sampling. They were produced during two experiments conducted in 1997 (experiment 1) and 1998 (experiment 2) where the families were generated according to a full factorial mating design that involved 3 dams x 9 and 10 sires, for experiment 1 and 2 respectively. The three dams and 6 of the sires (i.e. 18 families) were common to both year-experiments. All the breeders had been caught in the wild (West Mediterranean) with the exception of two females whose origin was not accurately known: they were either wild fish from West Mediterranean or cultured offspring from wild parents caught in this area. Embryos from each family were produced at the beginning of the natural spawning season (February): eggs were obtained by manual stripping of the females following hormonal induction of ovulation. Individual synchronous fertilizations of the eggs of each dam with the sperm of each of the sires were performed. Floating (alive) and sinking (dead) eggs were separated at $48 \mathrm{~h}$ post fertilization by decanting at a salinity of 38\%o (Chatain, 1994) and each experimental group received an equal quantity of eggs from each family as estimated from the volume of eggs as described in Saillant et al. (2002, 2003) thus resulting in an equal initial representation of each family in each group. Initial density in experiment 1 was 100 eggs/l. In experiment 2, it was 200 and 20 eggs/l respectively in the two density treatments tested. Broodstock management and protocols for hormonal induction of spawning, artificial fertilization and incubation of eggs are described in details in Saillant et al. (2002, 2003). 
Detailed protocols for subsequent phases of experiment 1 and 2 can also be found in Saillant et

2

al. (2002) and Saillant et al. (2003) respectively. Briefly, in experiment 1, two thermal treatments were applied: in the hot treatment (High Temperature, HT), temperature was maintained above $19^{\circ} \mathrm{C}$ from 19 days post fertilization (dpf) until the fish reach a mean Standard Length (SL) of $14 \mathrm{~cm}$ whereas in the cold treatment (Low temperature, LT) temperature was maintained at $13 \pm 1^{\circ} \mathrm{C}$ from fertilization until the fish reach a mean $\mathrm{SL}$ of $6.5 \mathrm{~cm}$. The LT group was then maintained under the same conditions as the HT group later on. The HT group included three replicate tanks (HT1, 2, 3) treated identically throughout the experiment (Figure 1). The replicate HT1 was lost at $468 \mathrm{dpf}$ due to a technical failure and was replaced by surplus fish from tank HT2 randomly sampled at the following biomass adjustment (504 dpf) and reared in the tank HT2b that was kept under the same conditions as applied to the other two replicates (HT2, HT3) until the end of the experiment (Figure 1).

(1)

(4)

In experiment 2, two density treatments were applied: the group HD was raised under a high density protocol that corresponds to the maximum rearing densities usually applied in aquaculture of sea bass until the fish reach a mean SL of $14.2 \mathrm{~cm}$ whereas the group LD was raised following a very low density pattern during the same period (final mean SL: $13.8 \mathrm{~cm}$ ). Rearing density varied in both treatments during the experiment due to zootechnical constraints but was maintained 5 to 15 higher in the group HD than in the group LD (Figure 1). The HD and LD groups included 3 and 2 replicate rearing tanks kept throughout the experiment. Experimental conditions within both experiments were identical between groups except for the environmental factor (temperature or density) tested; they corresponded to standard protocols applied currently in intensive culture of sea bass. Following the treatments, fish from both groups (HT/LT in experiment 1 and HD/LD in experiment 2) were maintained under identical conditions until 
sampling. Densities had to be regularly lowered in all groups in order to keep the biomass below threshold levels determined by taking into account oxygen demand of the fish at various stages of development. This was done by randomly discarding excess fish.

\subsection{Samplings and measurements}

(1)

A total of 3440 fish sampled in the various groups were used in the genetic analysis. Sampling for genotyping and pedigree analysis in both experiments is summarized in Table 1 and Figure 1. Sample size in individual tanks averaged 365 in experiment 1 and 193 in experiment 2.

In experiment 1, fish sampled from the replicate tanks HT1, 2, and 3 and from the tank LT were genotyped (Table 1). Tanks HT1 and HT2 and LT were sampled at a similar reference growth stage (mean SL between $20.0 \mathrm{~cm}$ for tank LT2 and $21.6 \mathrm{~cm}$ for tank HT2). The group HT was then sampled at two subsequent growth stages thus allowing to studying the evolution of genetic parameters with age: tank HT2 was sampled a second time when the fish reached a mean SL of $27.4 \mathrm{~cm}$ and a third time when they reach a mean SL of $32.6 \mathrm{~cm}$. At this stage, tank HT3 and HT2b also were sampled (Table 1). In tank HT1, measurements were taken at a mean SL of $16.0 \mathrm{~cm}$, and a second time at slaughtering $(20.6 \mathrm{~cm})$.

In experiment 2, samples from three replicate tanks raised under high density (HD1, 2, 3) and two replicate tanks raised under low density, (LD1, 2) were genotyped. Sampling occurred when the fish had reached a mean SL comparable to the reference growth stage in experiment 1 (20.5$21.1 \mathrm{~cm}$; Table 1, Figure 1).

For each sample, the fish were randomly selected within the tank under anesthesia. They were killed by immersion in 400 ppm phenoxy2ethanol, dissected for sexing, weighed and measured 
1 (SL). The phenotypic sex was identified as described in Saillant et al. (2002) and a small piece of

2 fin (c. $\left.25 \mathrm{~mm}^{2}\right)$ was sampled and kept in $95 \%$ ethyl alcohol for further genotyping.

2.3. Genotyping and pedigree analysis

5

$6 \quad$ Nuclear DNA was extracted from the fin clips as described in Saillant et al. (2002). Parents and

17 each individual sampled were assayed at 3 or 6 microsatellite loci described by Garcia de Leon et al. (1995). The loci were combined in two multiplexes (multiplexe1: Labrax 3, Labrax 13 and Labrax 29; multiplexe2: Labrax 6, Labrax 8 and Labrax 17) for run on an automatic sequencer ABI 377 (Perkins Elmer, Courtaboeuf, France). Procedures for primer labeling, PCR amplification and run and analysis of PCR products followed protocols detailed in Saillant et al. (2002). The genotypes obtained were used to assign fish sampled at slaughtering to their parents thanks to a personal program: $93.4 \%$ and $100 \%$ of the fish were unambiguously assigned to two parents using respectively Multiplexe 1 or the combination of Multiplexe 1 and Multiplexe 2.

\subsection{Data analysis}

Weight data were log transformed before analysis to stabilize heterogeneity of variances due to scale effects and datasets were checked for homoscedasticity and normality. The random components of phenotypic variance $\left(\sigma_{\mathrm{P}}^{2}\right)$ and their standard errors were estimated using the Restricted Maximum Likelihood method (REML) as implemented in VCE5 ® (Neumaier and Groeneveld, 1998) and using the following model:

$$
y_{i j k l m n}=\mu+\mathrm{Se}_{i}+s_{j}+d_{k}+\mathrm{G}_{l}+\mathrm{t}_{m}\left(\mathrm{G}_{l}\right)+e_{i j k l m n}(1)
$$


where $y_{i j k l m n}$ is an observation on the individual $\mathrm{n}, \mu$ is the overall mean, $\mathrm{Se}_{i}$ is the fixed effect

of phenotypic sex i, $s_{j}$ is the random effect of sire $\mathrm{j}, d_{k}$ is the random effect of dam $\mathrm{k}, \mathrm{G}_{l}$ is a fixed effect of experimental group 1 (when data from multiple experimental groups were used), $\mathrm{t}_{m}$ is the random effect of tank $\mathrm{m}$ (when multiple tanks were available within a given experimental group), and $e_{i j k l m n}$ is the residual random error term.

Preliminary analyses indicated that the sire $\mathrm{x}$ dam interaction effect was not significant in all datasets; this effect was therefore not included in the models used to generate the present estimates.

The additive genetic variance $\left(\sigma_{\mathrm{A}}^{2}\right)$ was estimated from the sire component of variance $\left(\sigma_{s}^{2}\right)$ through the relationship $\sigma_{\mathrm{A}}^{2}=4^{*} \sigma_{s}^{2}$ (Becker, 1984), and heritabilities were calculated as the ratio $h^{2}=\sigma_{\mathrm{A}}^{2} / \sigma_{\mathrm{P}}^{2} \cdot h^{2}$ was estimated in the 4 groups resulting from experiments 1 (HT and LT) and 2 (HD and LD), respectively. An overall estimate using data from all experimental groups and based on the 6 sires shared by the two year experiments was also calculated. Estimates of $h^{2}$ were also generated at each of the five age-sample available in group HT.

Tanks HT1 and HT2 were sampled at a similar size (20.6 and $21.6 \mathrm{~cm}$ respectively) although ages were different (468 dpf versus $504 \mathrm{dpf}$ ). They were therefore also combined in a single analysis during which the random tank effect in (1) was replaced by a fixed effect (age).

The additive genetic correlation between weight and length was estimated as the correlation among genetic values of the sires in a multitrait analysis as implemented in VCE5. Estimates were obtained at various ages in the group HT and based on the above described model. Phenotypic correlation between these two traits was calculated using Pearson's linear correlation coefficient in SAS® (SAS Institute Inc., Cary, NC, USA). 
3

.

Genetic correlations were examined among pairs of environments (i.e. among pairs of groups HT, LT, HD, LD) and among growth stages (age) using the samples available in the group HT: additive genetic correlations were estimated as the ratio of the observed covariance (calculated by linear regression analysis) of Estimated Breeding Values (EBV) of the sires, to the product of the square root of the estimated sire variance ( $\sigma_{s}^{2}$, estimated as indicated above) in each of the two groups considered (Lynch and Walsh, 1998). Best Linear Unbiased Predictors for the sires were computed in PEST 4.2.3 (Groeneveld and Kovac, 1990) using the model described above and used as EBV in the calculation of genetic correlations. Standard errors $\left(\sigma_{r_{a}}\right)$ of the estimated genetic correlations $\left(r_{a}\right)$ were approximated by the following formula (Falconer and McKay, 1996): $\sigma_{r_{a}}=\frac{1-r_{a}^{2}}{\sqrt{2}} \sqrt{\left[\frac{\sigma_{\left(h_{X}^{2}\right)} \sigma_{\left(h_{Y}^{2}\right)}}{h_{X}^{2} h_{Y}^{2}}\right]}$

Where $\sigma_{\left(h_{x}^{2}\right)}$ and $\sigma_{\left(h_{Y}^{2}\right)}$ denote standard errors of heritability estimates in each of the two groups considered and $h_{X}^{2}$ and $h_{Y}^{2}$ the corresponding heritability estimates.

\section{Results}

All datasets displayed unequal contributions of sexes and individual families. The percentage of females was very low in all groups (6 to $30 \%$, table 1). The proportion of offspring assigned to dam $\mathrm{C}$ was the lowest in both experiments (20 and $18 \%$ of the total in experiment 1 and 2 respectively) whereas 50 and $31 \%$ of the offspring were assigned to Dam A and B respectively in experiment 1, versus 35 and $47 \%$ respectively in experiment 2 . The proportions of offspring assigned to individual sires varied from 7 (sire 2) to $14 \%$ (sire 1) in experiment 1 whereas in experiment 2 they were from 7 (sire 2) to $15 \%$ (sire 9). 


\subsection{Genetic parameters for body weight and length recorded at various ages}

Heritability was estimated at 5 different ages in the HT group of experiment $1(341,468,504$,

5601 and $818 \mathrm{dpf}$ mean individual weights from $90.0 \mathrm{~g}$ at $341 \mathrm{dpf}$ to $744.2 \mathrm{~g}$ at $818 \mathrm{dpf}$, table 2).

$6 \quad h^{2}$ estimates were all significantly higher than 0 . For $\ln \mathrm{W}$, the estimated values ranged between

$7 \quad 0.21 \pm 0.10(\operatorname{tank} H T 1,341 \mathrm{dpf})$ and $0.58 \pm 0.23(\operatorname{tank} \mathrm{HT} 2,601 \mathrm{dpf})$, and they averaged 0.39.

$8 \quad h^{2}$ estimates tended to increase with the age of the fish $(0.21 \pm 0.10$ at $341 \mathrm{dpf}$ to $0.56 \pm 0.20$ at

$9818 \mathrm{dpf}$, Spearman rank correlation $r s=0.90, P=0.04)$.

10 Similar results were observed for Standard Length of the fish which was highly correlated with $11 \ln \mathrm{W}$ at all stages examined (genetic correlation $0.91<r_{a}<1.00$; phenotypic correlation $120.91<r<0.95, P<0.001)$. Thus further results are presented only for $\ln \mathrm{W}$.

Estimates of genetic correlations between EBV of $\ln \mathrm{W}$ of half sib families recorded at various ages ranged between 0.61 and 0.85 (Table 3). They averaged 0.70. All 10 correlations 16 estimated, were significant.

$h^{2}$ was estimated at a reference size (20.0-21.6 cm mean standard length) in two experiments

carried out in 1997 and 1998 respectively where two thermal treatments (1997) and two density treatments (1998) were applied. Estimates were significantly different from zero in both yearexperiment and in all environmental conditions tested and they averaged 0.43 (range 0.31-0.60) 
1 (Table 4). An overall estimate based on the six sires available for both year experiments was 0.29 $2 \pm 0.13$.

3 In experiment $1, h^{2}$ estimates tended to be higher in the LT group $(0.50 \pm 0.19)$ than in the HT group $(0.31 \pm 0.12)$ and the correlation of the EBVs estimated in the two groups was $0.49 \pm 0.21$ (Table 5).

Similarly, in experiment 2, heritability estimate was higher in the LD group than in the HD group $(0.60 \pm 0.22$ versus $0.32 \pm 0.12$, Table 4$)$ and genetic correlation between the two density treatments was $0.51 \pm 0.19$ (Table 5).

Correlations between EBV estimated in 1997 (experiment 1) and 1998 (experiment 2) were between 0.01 and 0.45 (Table 5) and they were non significant.

\section{Discussion}

Heritability of body size was estimated during two experiments where 27-30 families were raised under various environmental conditions. Experimental groups were raised under two temperatures in experiment 1 (1997) whereas two density regimes were implemented in experiment 2 (1998). $h^{2}$ was estimated at a mean size of $20.0-21.6 \mathrm{~cm}$ in all groups. Estimates ranged between $0.31 \pm 0.12-0.60 \pm 0.22$ while an overall estimate based on data from both yearclasses was $0.29 \pm 0.13$ thus indicating an important additive genetic component of growth rate of the sea bass in all conditions tested. These estimates constitute the first report of heritability of growth rate in sea bass to date. Heritability values obtained here are in the upper range of unbiased a priori estimations of $h^{2}$ in other fish species (e.g. 0.1-0.3 in salmonids, Gjedrem, 
6

2000; 0.33 in the common carp, Vandeputte et al., 2004; 0.20 in Tilapia, Gall and Bakar, 2002).

Our estimates are unbiased by dominance or maternal non genetic effects since they are based on the sire component of variance only. Also, the use of communal rearing conditions for all the families tested here prevented occurrence of early common environment effect that could be confounded with genetic values. However, our estimates are based on $9-10$ sires only and thus have to be taken in caution as they may reflect a particular large genetic variance in this specific set of breeders. Also, most estimations of $h^{2}$ to date have been carried out using families reared in separate tanks. The high values obtained here might thus reflect an emphasis of the genetic variance when estimated under communal rearing conditions. However, some studies compared heritability estimates obtained under communal rearing conditions to estimates from families reared separately (Herbinger et al., 1999; Koedprang et al., 2000). In all three experiments estimates were lower under communal rearing conditions although $h^{2}$ was probably over estimated for families raised in separate tanks in Herbinger et al. (1999) since families were not replicated. There is thus no evidence to date that $h^{2}$ be over-estimated when assessed under communal rearing conditions as compared to separate rearing protocols.

The high values of $h^{2}$ obtained here would suggest that rapid gains could be achieved through selective breeding for growth rate in sea bass. However the translation of these high a priori estimates of heritability into corresponding high values of realized heritability (and genetic progress) in selection operations could be limited in the presence of important genotype environment interactions. Estimates of correlations of EBVs between environments were moderate $(0.01-0.51)$ suggesting that such interactions may occur in sea bass. This result would suggest that the response to selective breeding would be limited if the environment where breeding values are evaluated and the one where offspring of selected fish are grown do differ. 
1 The actual degree of correlation among environments is however not very accurately estimated

2 here as indicated by the large approximate standard errors obtained. This low accuracy is likely

3 due in part to a limited number of sires available for the estimation ( 9 - 10 between treatments

4 within years and 6 only between years). Also, the low values of the estimates might reflect an

5 under-estimation of the estimated correlations that was based on correlations of unitrait EBVs as

6 pointed out by Fishback et al. (2002). However, the magnitude of potential bias is expected to be

7 minor when heritability is high and family sizes are large (Lynch and Walsh, 1998) which is the

8 case in our study (heritability estimates are between $0.31-0.60$ and sire half sib families are larger

9 than 50 individuals on average). Also, correlations between environments/years were consistently

much lower than correlations between ages in a given environment (average 0.38 versus 0.70 )

11 suggesting that rearing environment did impact genetic values. This result may reflect the fact that the protocols applied in both experiments resulted in extremely different growth conditions

13 (e.g. see group LT, experiment 1). But such extreme variations in environmental conditions are 14 unlikely to be encountered between aquaculture sites or between years within sites so that selected offspring may not be raised in such variable environments in industrial aquaculture. Higher correlations might therefore be observed when the environmental conditions compared are not as extreme as those tested here. Overall, the present results however suggest that some genotype $\mathrm{x}$ environment may occur in the sea bass and would need to be further quantified using a more powerful design for potential impacts on selective breeding operations.

Heritability estimates tended to be higher under low density than those obtained under high density (0.6 versus 0.3$)$ suggesting that the expression of the genetic potential could require decreasing rearing density. However, as discussed above, moderate correlation between high and low density might prevent efficient transfer of genetic progress to commercial hatcheries where, high density are usually applied. $h^{2}$ tended also to be higher under low temperature but the low 
temperature tested in this experiment led to an extremely slow growth and are incompatible with commercial production.

Heritability was also estimated at various ages in the group HT. Estimates increased with age. The same observation was made by Su et al. (1996) although fish were smaller and younger (final mean weight $136 \mathrm{~g}$ ) than in the present experiment (final mean weight $738 \mathrm{~g}$ ). This could be due to a lower ratio of weight or length measure errors to the individual measure in bigger fish resulting in an increased accuracy of the measurements in older fish. This result could also reflect an amplification of the differences between families who differ in genetic values with regards to the total phenotypic variance. An opposite result would have been expected in the presence of important interactions with sexual maturation i.e. heritability estimates would be expected to decrease due to differential reproductive investment between families (McKay et al., 1986). Sexual maturation was not assessed in our experiments but should have been minor under the thermal conditions applied $\left(>19^{\circ} \mathrm{C}\right)$. Eventual investment in gamete production did not actually result in lower estimates of heritability on body weight or length. This result suggest that sexual maturation had a minor impact on somatic growth in sea bass during the growth phase examined here as already observed at a similar growth stage by Saillant et al. (2001).

Genetic correlations between ages were high and all significant. Breeding values at various ages were estimated in different tanks and may therefore have been underestimated if genotype $\mathrm{x}$ environment interactions occurred. However, the tanks sampled were treated identically throughout the experiment. Eventual environmental differences between them were therefore certainly minimal, leaving little potential impact of genotype $\mathrm{x}$ environment interactions on the estimated correlations. Overall, the relatively high values estimated here suggest that genetic 
values are stable within the age range sampled and can thus be estimated early in the growing cycle of the sea bass (as early as $341 \mathrm{dpf}, 90 \mathrm{~g}$ ).

\section{Acknowledgments}

(1)

We thank Yves Amigues and Maryvonne Boscher (G.I.E. LABOGENA) for their technical assistance during genotyping. We also thank Marie Odile Vidal, Sylvain Rols, Cyril Przybyla, Patrik Legall, Christian Fauvel and Jean-Claude Falguière for their help with the zootechnical phases. Eric Saillant was supported by the French hatcheries - Ecloserie Marine de Gravelines (Gravelines, France), Méditerranée Pisciculture (Salses, France), GAEC Poissons du Soleil (Balaruc les Bains, France) and the National Association for Technical Research (Grant CIFRE $\mathrm{n}^{\circ}$ 96581). This study was carried out with financial support from the French Ministery of Education, Research and Technology and the French Ministery of Agriculture: "Agriculture Demain” n 95.G.0108 and Transfert in Biotechnology 99.HD.0192. SYSAAF contributions are also supported by OFIMER.

\section{References}

Becker, W.A., 1984. Manual of quantitative genetics. Academic Enterprises, Pullman, Washington, $188 \mathrm{pp}$. 
Chatain, B, 1994. Estimation et amélioration des performances zootechniques de l'élevage larvaire de Dicentrarchus labrax et de Sparus auratus. Thèse Doctorat d'Etat. Marseille, Univ., Aix Marseille 1, France, 199 pp.

Chevassus, B., Dupont-Nivet, M., Mauger, S., Haffray, P., Vandeputte, M., 2002. Estimation of heritabilities in two groups of rainbow trout (Oncorhynkus mykiss) with families mixed together since eyed stage. In: $7^{\text {th }}$ World Congress on Genetics Applied to Livestocks Production. Montpellier, August 19-23, 2002. Book of abstracts, Communication n ${ }^{\circ} 06-09, \mathrm{p}$ 147.

Estoup, A., Gharbi, K., SanCristobal, M., Chevalet, C., Haffray, P., Guyomard, R., 1998. Parentage assignment using microsatellites in turbot (Scophtalmus maximus) and rainbow trout (Oncorhynchus mykiss) hatchery populations. Can. J. Fish. Aquat. Sci. 55, 715-725.

Falconer, D.S., Mackay, T.F.C., 1996. Introduction to quantitative genetics ( $4^{\text {th }}$ Edition). Pearson Education Limited, Harlow, England, 464 pp.

Fishback, A., Danzmann, R.G., Ferguson, M.M., Gibson, J.P., 2002. Estimates of genetic parameters and genotype by environment interactions for growth traits of rainbow trout (Oncorhynchus mykiss) as inferred using molecular pedigrees. Aquaculture 206, 137-150.

Gall, G.A.E., Bakar, Y., 2002. Application of mixed-model techniques to fish breed improvement: analysis of breeding-value selection to increase 98-day body weight in tilapia. Aquaculture 212, 93-113.

Garcia de Leon, F.J., Dallas, J.F., Chatain, B., Canonne, M., Versini, J.J., Bonhomme, F., 1995. Development and use of microsatellite markers in sea bass, Dicentrarchus labrax (Linneaus, 1758) (Perciformes: Serranidae). Mol. Mar. Biol. Biotech. 4(1), 62-68. 
Garcia de Leon, F.J., Canonne, M., Quillet, E., Bonhomme, F., Chatain, B., 1998. The application of microsatellites markers to breeding programmes in the sea bass Dicentrarchus labrax. Aquaculture 159, 303-316.

Gjedrem, T., 2000. Genetic improvement of cold-water fish species. Aquac. Res., 31, 25-34.

Gorshkov, S., Gorshkova, G., Meiri, I., Gordin, H., 2004. Culture performance of different strains and crosses of the European sea bass (Dicentrarchus labrax) reared under controlled conditions at Eilat, Israël. J. Appl. Ichthyol. 20, 194-203.

Groeneveld, E., Kovac, M., 1990. A generalized computing procedure for setting up and solving mixed linear models. J. Dairy Sci., 73, 513-531.

Herbinger, C.M., O'Reilly, P.T., Doyle, R.W, Wright, J.M., O'Flynn, F., 1999. Early growth performance of Atlantic salmon full-sib families reared in single family tanks versus in mixed family tanks. Aquaculture, 173, 105-116.

Herbinger, C.M., Doyle, R.W., Pitman, E.R., Paquet, D., Mesa, K.A., Morris, D.B., Wright, J.M., Cook, D., 1995. DNA fingerprint based analysis of paternal and maternal effects on offspring growth and survival in communally reared rainbow trout. Aquaculture, 137, 245-256.

Knibb, W, 1998. Genetic improvement of marine fish - which method for industry? Aquac. Res., $31,11-23$.

Koedprang, W., Ohara, K., Taniguchi, N., 2000. Genetic and environmental variances on growth and reproductive traits of silver crucian carp Carassius langsdorfii using communal and separate rearing systems. Fisheries Sci., 66, 1092-1099.

Lynch, M., Walsh, B., 1998. Genetics and Analysis of Quantitative Traits. Sinauer Associates Inc., Sunderland, 948 pp.

McKay, L.R., Ihssen, P.E., Friars, G.W., 1986. Genetic parameters of growth in rainbow trout, Salmo gairdneri, as a function of age and maturity. Aquaculture, 58, 241-254. 
Neumaier, A., Groeneveld, B., 1998. Restricted Maximum Likelihood Estimation of Covariances in Sparse Linear Models. Genet. Sel. Evol., 30, 3-26.

Saillant, E., Fostier, A., Menu, B., Haffray, P., Chatain, B., 2001. Sexual growth dimorphism in the European sea bass (Dicentrarchus labrax). Aquaculture, 202, 371-387.

Saillant, E., Fostier, A., Haffray, P., Menu, B., Thimonier, J., Laureau, S., Chatain, B., 2002. Temperature effects and genotype temperature interactions on sex-determination in the European Sea Bass (Dicentrarchus labrax L.). J. Exp. Zool., 292, 494-505.

Saillant, E., Fostier, A., Haffray, P., Menu, B., Laureau, S., Thimonier, J., Chatain, B., 2003. Effects of rearing density, size grading and parental factors on Sex Ratios of the sea bass (Dicentrarchus labrax L.) in intensive aquaculture. Aquaculture, 221, 183-206.

Su, G.S., Liljedahl, L.E., Gall, G.A.E., 1996. Genetic and environmental variation of body weight in rainbow trout (Oncorhynchus mykiss). Aquaculture, 144, 71-80.

Vandeputte, M., Dupont-Nivet, M., Chatain, B., Chevassus, B., 2001. Setting up a strain-testing design for the sea bass, Dicentrarchus labrax: a simulation study. Aquaculture, 202, 329342.

Vandeputte, M., Kocourb, M., Mauger, S. , Dupont-Nivet, M., De Guerry, D., Rodina, M., Gela, D., Vallod, D., Chevassus, B., Linhart, O., 2004. Heritability estimates for growth-related traits microsatellite parentage assignment in juvenile common carp (Cyprinus carpio L.). Aquaculture, 235, 223-236.

Wohlfarth, G.W., Hulata, G., 1989. Selective breeding of cultivated fish. In: Shilo, M., Sarig, S. (Eds.), Fish Culture in Warm Water Systems: Problems and Trends. CRC Press, Boca Raton, pp. 2163. 
Fig. 1. Summary of experimental protocols for two experiments where 27-30 families of sea bass were raised under communal testing conditions. White squares indicate replicate tanks within a treatment and samplings stages are indicated in grey squares.

19

20 
1

2

3

4

5

6

7

8

9

10

11

12

13 
Experiment 1 (1997)

Dam A, B, C

Sire 123456789

High Temperature $\left(\mathrm{HT}>19^{\circ} \mathrm{C}\right)$ versus Low Temperature (LT $\left.13^{\circ} \mathrm{C}\right)$
Experiment 2 (1998)

Dam A, B, C

Sire 45678910111213

High Density (HD) versus Low Density (LD)
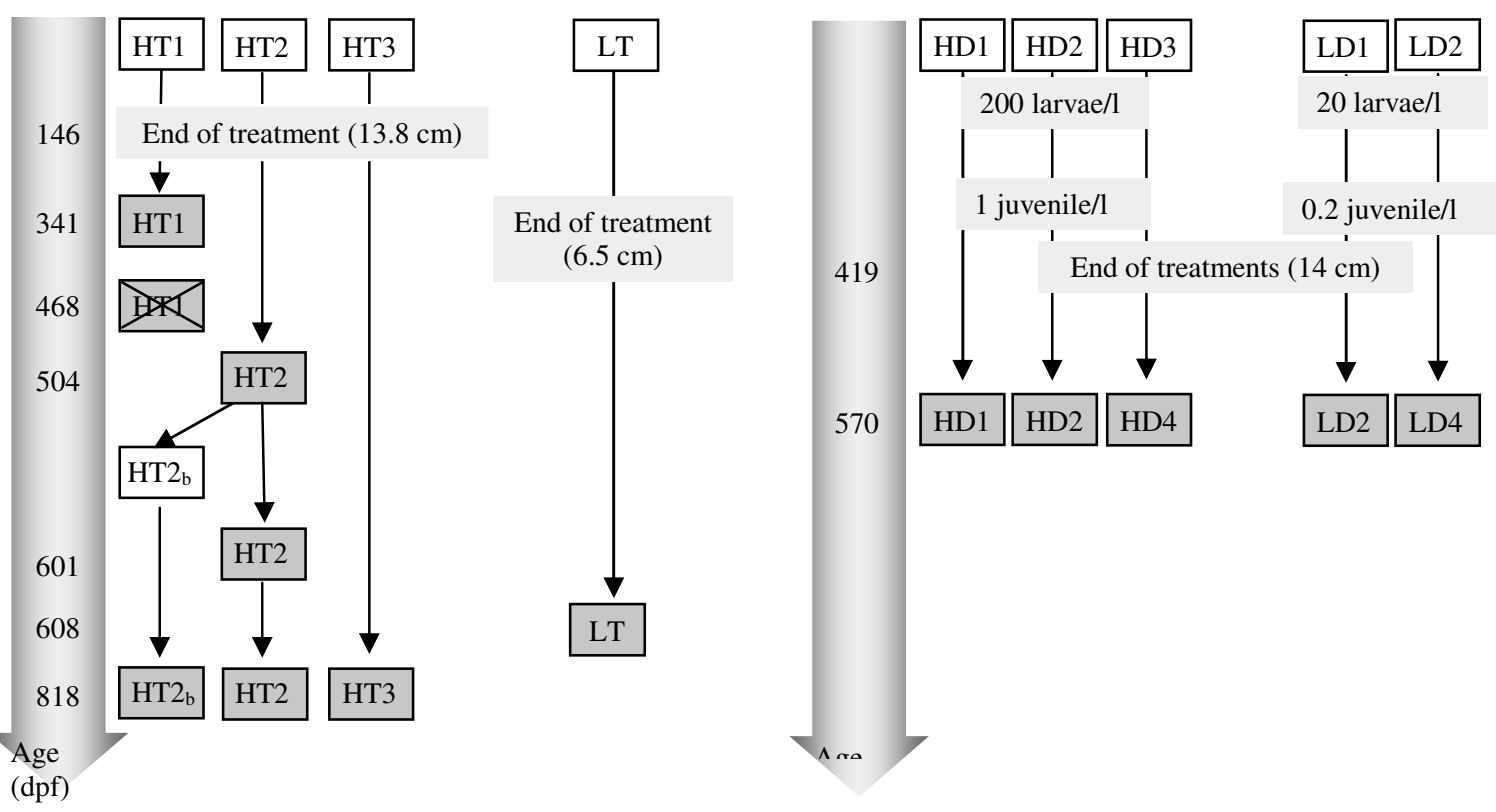
1 Table 2. heritabilities and \pm S.E. of neperian logarithm of weight (lnW) and Standard Length (SL)

2 estimated at various ages (group HT, 1997 experiment).

\begin{tabular}{cccc}
\hline Age (dpf) & tank & $\ln \mathrm{W}$ & SL \\
\hline 341 & HT1 & $0.21 \pm 0.10$ & $0.18 \pm 0.09$ \\
468 & HT1 & $0.26 \pm 0.12$ & $0.21 \pm 0.10$ \\
504 & HT2 & $0.32 \pm 0.14$ & $0.24 \pm 0.11$ \\
601 & HT2 & $0.58 \pm 0.23$ & $0.56 \pm 0.22$ \\
818 & HT2, HT2b and HT3 & $0.56 \pm 0.20$ & $0.40 \pm 0.16$
\end{tabular}

3

dpf: days post fertilization

4 
1 Table 3. Genetic correlations for $\ln \mathrm{W}$ recorded at various ages (in days post fertilization) during 2 experiment 1 (1997) in the HT group.

\begin{tabular}{llllll}
\hline Age (tanks available) & 818 (HT2, HT2b, HT3) & 601 (HT2) & 504 (HT2) & 468 (HT1) & 341 (HT1 ) \\
\hline 818 (HT2, HT2b, HT3) & $0.76 \pm 0.11$ & $0.85 \pm 0.08$ & $0.67 \pm 0.16$ & $0.64 \pm 0.17$ \\
601 (HT2) & & $0.79 \pm 0.1$ & $0.62 \pm 0.19$ & $0.61 \pm 0.26$ \\
504 (HT2) & & & $0.76 \pm 0.14$ & $0.71 \pm 0.16$ \\
468 (HT1) & & & & $0.63 \pm 0.20$ \\
\hline
\end{tabular}

3

4

5

6 
1 Table 4. Heritability $\mathrm{h}^{2} \pm$ S.E of neperian logarithm of weight $(\ln \mathrm{W})$ at a mean length of 20.0$2 \quad 21.6 \mathrm{~cm}$ estimated in different environments: High (HT) versus low (LT) temperature 3 (experiment 1, 1997) and High (HD) versus low (LD) density (experiment 2, 1998).

\begin{tabular}{ccc}
\hline & group & $h^{2} \ln W$ \\
\hline 1997 & HT & $0.31 \pm 0.12$ \\
& LT & $0.50 \pm 0.19$ \\
1998 & HD & $0.32 \pm 0.12$ \\
& LD & $0.60 \pm 0.22$ \\
\hline
\end{tabular}

4 5 
4 Table 5. Estimates of additive genetic correlations for $\ln \mathrm{W}$ between environments-years. High 5 (HT) versus low (LT) temperature (experiment 1, 1997) and High (HD) versus low (LD) density 6 (experiment 2, 1998).

\begin{tabular}{|c|c|c|c|c|}
\hline & & 1997 & 1998 & \\
\hline & & LT & HD & LD \\
\hline \multirow{2}{*}{1997} & HT & $0.49 \pm 0.21$ & $0.40 \pm 0.23$ & $0.45 \pm 0.21$ \\
\hline & $\mathrm{LT}$ & & $0.01 \pm 0.26$ & $0.45 \pm 0.21$ \\
\hline 1997 & HD & & & $0.51 \pm 0.19$ \\
\hline
\end{tabular}

7 
Table 1. Summary statistics (Number of fish $N$, Percentage of females (\% $q$ ), Mean Weight/Standard Length \pm Standard Deviation (SD) for males, females and the overall sample) for samples from 27 (1997 experiment) or 30 (1998 experiment) families raised in the same tanks from fertilization later on. The groups were raised under high (HT) or low (LT) temperature in 1997 and under high (HD) or low (LD) density in 1998.

\begin{tabular}{|c|c|c|c|c|c|c|c|c|c|c|c|}
\hline \multirow[t]{2}{*}{ Year } & \multirow[t]{2}{*}{$\mathrm{Trt}^{\mathrm{t}}$} & \multirow[t]{2}{*}{ Age } & \multirow[t]{2}{*}{ Tank } & \multirow[t]{2}{*}{$N$} & \multirow[t]{2}{*}{$\%$ q } & \multicolumn{3}{|c|}{ Mean Weight \pm SD $(g)$} & \multicolumn{3}{|c|}{ Mean Standard Length \pm SD $(\mathrm{cm})$} \\
\hline & & & & & & Both sexes & Males & Females & Both sexes & Males & Females \\
\hline \multirow[t]{8}{*}{1997} & LT & 608 & LT1 & 495 & 12 & $197.9 \pm 049.0$ & $195.7 \pm 048.7$ & $214.7 \pm 049.0$ & $20.0 \pm 1.7$ & $20.0 \pm 1.7$ & $20.4 \pm 1.5$ \\
\hline & HT & 341 & $\mathrm{HT} 1^{\mathrm{a}}$ & 442 & 38 & $090.0 \pm 033.6$ & $076.9 \pm 025.1$ & $111.1 \pm 034.9$ & $16.0 \pm 1.9$ & $15.3 \pm 1.5$ & $17.2 \pm 1.7$ \\
\hline & & 468 & HT1 & 442 & 38 & $185.8 \pm 062.4$ & $160.5 \pm 045.9$ & $226.3 \pm 064.2$ & $20.6 \pm 2.1$ & $19.8 \pm 1.7$ & $21.9 \pm 1.9$ \\
\hline & & 504 & HT2 & 535 & 30 & $209.4 \pm 071.4$ & $185.1 \pm 054.2$ & $267.0 \pm 074.3$ & $21.6 \pm 2.2$ & $20.9 \pm 1.9$ & $23.2 \pm 2.0$ \\
\hline & & 601 & HT2 & 312 & 32 & $458.9 \pm 136.6$ & $411.7 \pm 099.6$ & $558.9 \pm 150.5$ & $27.4 \pm 2.3$ & $26.6 \pm 1.9$ & $29.0 \pm 2.1$ \\
\hline & & 818 & HT2 & 267 & 32 & $728.1 \pm 233.4$ & $633.4 \pm 173.3$ & $927.4 \pm 218.3$ & $32.6 \pm 3.2$ & $31.4 \pm 2.7$ & $35.2 \pm 2.6$ \\
\hline & & 818 & HT3 & 267 & 37 & $746.6 \pm 224.6$ & $648.8 \pm 168.4$ & $912.6 \pm 210.5$ & $32.6 \pm 2.8$ & $31.5 \pm 2.4$ & $34.6 \pm 2.5$ \\
\hline & & 818 & HT2b & 150 & 40 & $742.4 \pm 248.2$ & $618.2 \pm 197.2$ & $928.6 \pm 195.3$ & $32.6 \pm 3.2$ & $31.1 \pm 2.9$ & $34.9 \pm 2.3$ \\
\hline \multirow[t]{5}{*}{1998} & LD & 570 & LD1 & 200 & 18 & $178.8 \pm 054.4$ & $170.5 \pm 050.1$ & $217.8 \pm 057.3$ & $20.8 \pm 1.9$ & $20.6 \pm 1.8$ & $22.2 \pm 1.7$ \\
\hline & & 570 & LD2 & 187 & 10 & $171.7 \pm 058.2$ & $164.8 \pm 051.1$ & $233.0 \pm 080.2$ & $20.5 \pm 2.0$ & $20.3 \pm 1.8$ & $22.6 \pm 2.5$ \\
\hline & HD & 570 & HD1 & 196 & 8 & $190.7 \pm 056.6$ & $186.2 \pm 052.9$ & $245.3 \pm 071.6$ & $21.1 \pm 1.9$ & $20.9 \pm 1.8$ & $22.9 \pm 2.1$ \\
\hline & & 570 & HD2 & 196 & 6 & $185.8 \pm 053.1$ & $183.2 \pm 052.2$ & $229.7 \pm 051.8$ & $20.8 \pm 1.8$ & $20.8 \pm 1.7$ & $22.4 \pm 1.7$ \\
\hline & & 570 & HD3 & 183 & 21 & $187.5 \pm 061.0$ & $178.1 \pm 051.6$ & $223.3 \pm 079.4$ & $20.9 \pm 2.0$ & $20.6 \pm 1.8$ & $22.0 \pm 2.4$ \\
\hline
\end{tabular}

Trt $^{\mathrm{t}}$ : treatment; ${ }^{\text {a }}$ : Fish individually tagged at $341 \mathrm{dpf}$ and measured again at $468 \mathrm{dpf}$. 